\title{
The virtual earth. The case study of the Rose garden in Alcoy
}

\author{
Maite Palomares Figueres, Ciro Vidal Climent, Ivo Vidal Climent
}

Escuela Técnica Superior de Arquitectura, Universitat Politècnica de València. Valencia, Spain

E-mail: mapafi@upv.es, civicli@pra.upv.es, ivvicli@pra.upv.es

\begin{abstract}
The Viaducte des Arts at the Coulée verte René-Dumont in Paris (1993) or the High Lane in New York (2009) have managed to increase the urban quality in large areas of their cities. In both cases, a costly infrastructure of disused highways was reused to generate a planted promenade or a linear park getting back a dynamic point of view at a height of about ten meters above the city. With the perspective of the time elapsed since its construction we must conclude that, although their structural singularity does not make them exportable to other cities, their simple constructive conception does. In them there is a common denominator that we can define as virtual earth. That concept is linked to the current technical capacity to generate green spaces over spaces of any other use. It is a new fertile land that allows the resolution of the complex problem produced by the accumulation of uses and requirements in the same place. In the present study case the objective is to recover an urban garden in Alcoy, known as la the Rose garden, without having to reduce the number of parking spaces of the garage that was built under it. At the same time, the project has to meet the surface requirements of an earthen mantle necessary to consider restored the use of green zone. The solution solves in eighty centimeters of thickness a manufactured earth capable of assuming bulky trees that return to the city and to the Rose garden their lost atmosphere.
\end{abstract}

Keywords: virtual earth, green space, urban garden, underground parking

\section{Prolegomena}

The Rose Garden (Rosaleda) or Constitution square (Plaza de la Constitución) was a green area permanently used by the children of the neighborhood because it provided a generous play area safe from cars. In October 2001 the City Council approved the project for the implementation of an underground car park and in two years the new plaza was inaugurated with the concession of the garage for the next twenty-five years. Immediately the environmental group La Carrasca began a long legal battle to restore the status of green zone according to the parameters stipulated in the municipal building regulations. After fourteen years the citizens have had the necessary time to see the darker side of the built project.
It is now in a state of considerable deterioration, both inside the garage due to numerous leaks, as well as outside due to the graphiti and vandalized walls. On the other hand, as a parking only one sixth or fifth of its capacity is used. For the outer spaces we can verify that the design strategy of dividing the space into two platforms united by a monumental staircase was a mistake since that staircase has become an additional architectural barrier that separates both levels instead of uniting them. Fortunately the cafeteria has remained in full activity linked to the pedestrian traffic of the sidewalks because citizens go to the kiosk with the usual custom they had before the works. 

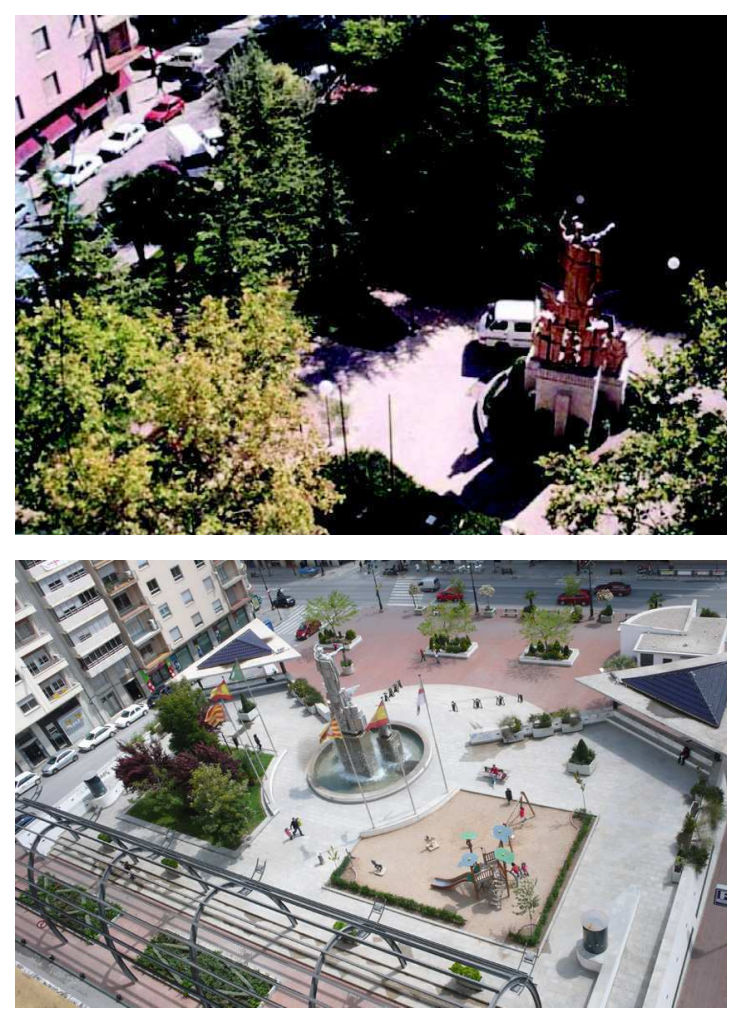

Figure 1.

The Rose Garden on its original state and after its transformation into a parking. $\mathbb{C} V \mathrm{VV}$

\section{References of the project}

If we remember the popular acceptance of the viaduct of the Arts in the Coulée verte René-Dumont in Paris (1993) or the New York High Lane (2000) we can identify an evaluate some of the reasons for their success. In addition to reusing an old depreciated infrastructure naturally assumed by the city, there is also their evident and polite distance from the car. The work of integrating the various uses and the connection with the city responds to its local conditions, however, what is common in both cases is the construction of a stratum of land located above the road surface. This virtual mantle, depending on the thickness, the selection of land and the irrigation system, allows the stability of a vast diversity of plantations. Therefore it is the singular element that at present we must have in mind an study for all the urban conflicts in which the presence of the traffic invades an extensive surface turning it into an unusable

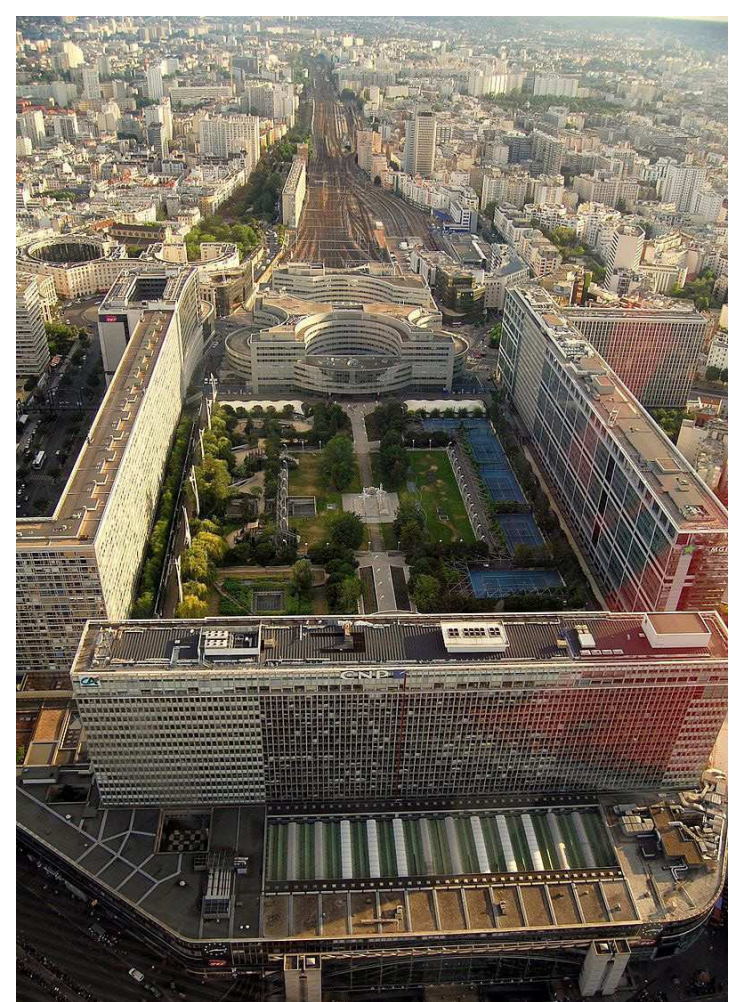

Figure 2.

The Atlantic garden on the roof of Montparnasse Station in Paris. Owikipedia

and inhospitable zone for the citizen. Although at first it can seem contradictory, these surfaces can gain new value and use through the implementation of an artificial elevated green area wide enough to mask its lower uses. In this sense the Atlantic garden is a green space that covers the complicated railway infrastructure of Montparnasse station where the TGV links Paris with the Atlantic coast. The $35,000 \mathrm{~m} 2$ deck contains large landscaped spaces as well as some areas for games and sports. It was designed by landscape architects François Brun and Michel Péna in 1995 with quite adverse external conditions as it has an almost continous perimeter of tall buildings that hinder the entry of sun. Apart from the inevitable noises the user of the upper garden is no longer aware of the lower activity as a train station, and this is the reason why that humble layer of earth becomes such a powerful tool for the urban planner. 


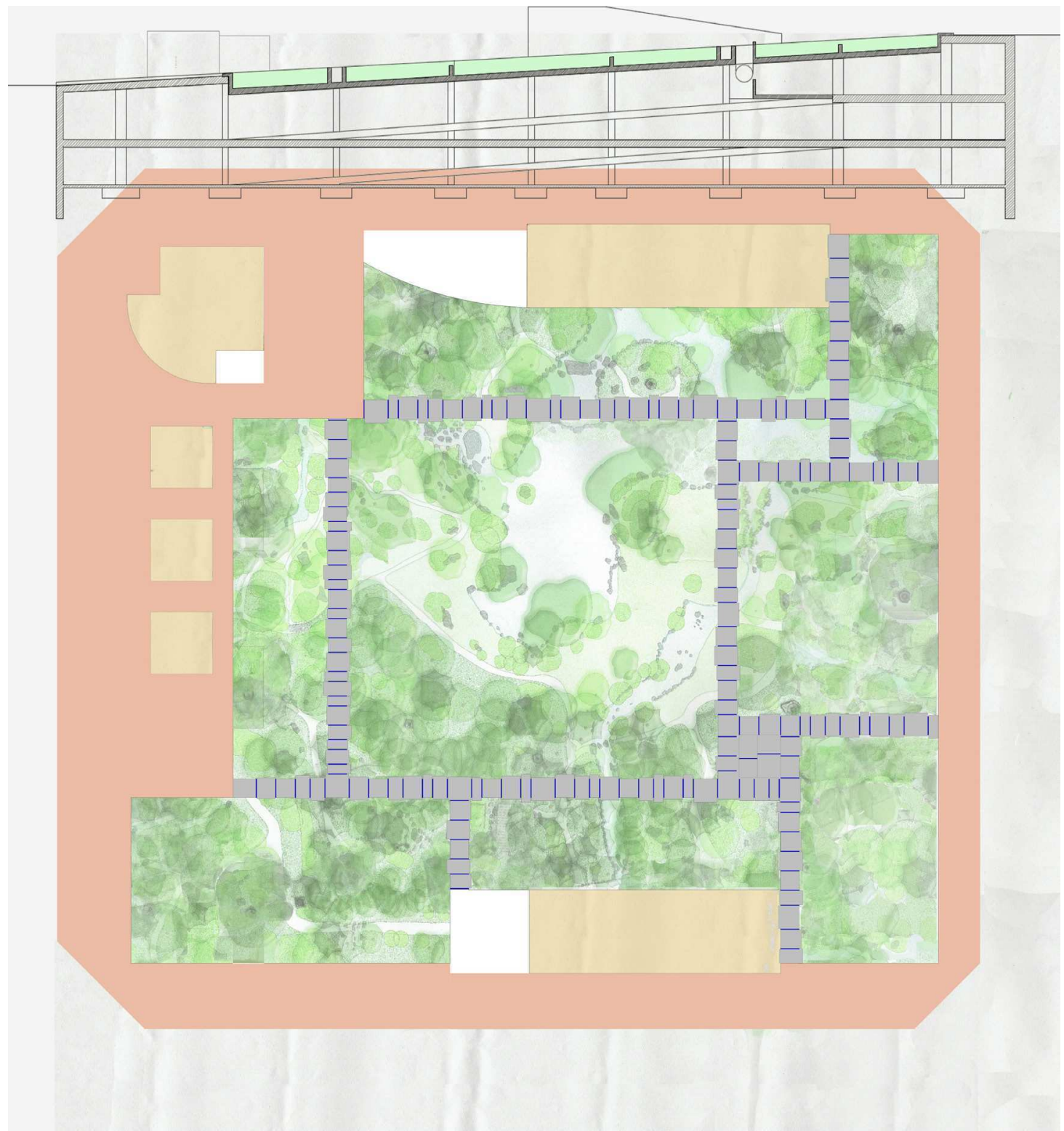

Figure 3.

Plan and section of the new project for the Rose Garden and garage. OVVV

\section{Decisions of the project}

The simplest solution to the conflict of interests that concentrate in Constitution Square consists of rendering it compatible the use of a green zone with the concession of the underground garage. The new project aims to return to the old garden its condition of urban green area of public use according to the court order that demands the restoration of the green area of the Rose Garden. To do this, it is necessary that at least half of the square must be gardened with a layer of earth of a minumum of eighty centimeters whose surface is at the same level as the sidewalks that surround it.

Once accepted the strategic convenience of the demolition of the two platforms that form the current roof of the garage, it is then possible to think of a new and unique inclined landscaped surface with the same slope as the two side streets, Góngora and Joan Valls. Then all the decisions of the project prioritize the needs of the garden and adapt the needs of the parking, such as the accesses and vents, to the flat topography that the new square assumes when modifying its levels according to the levels of the surrounding streets 

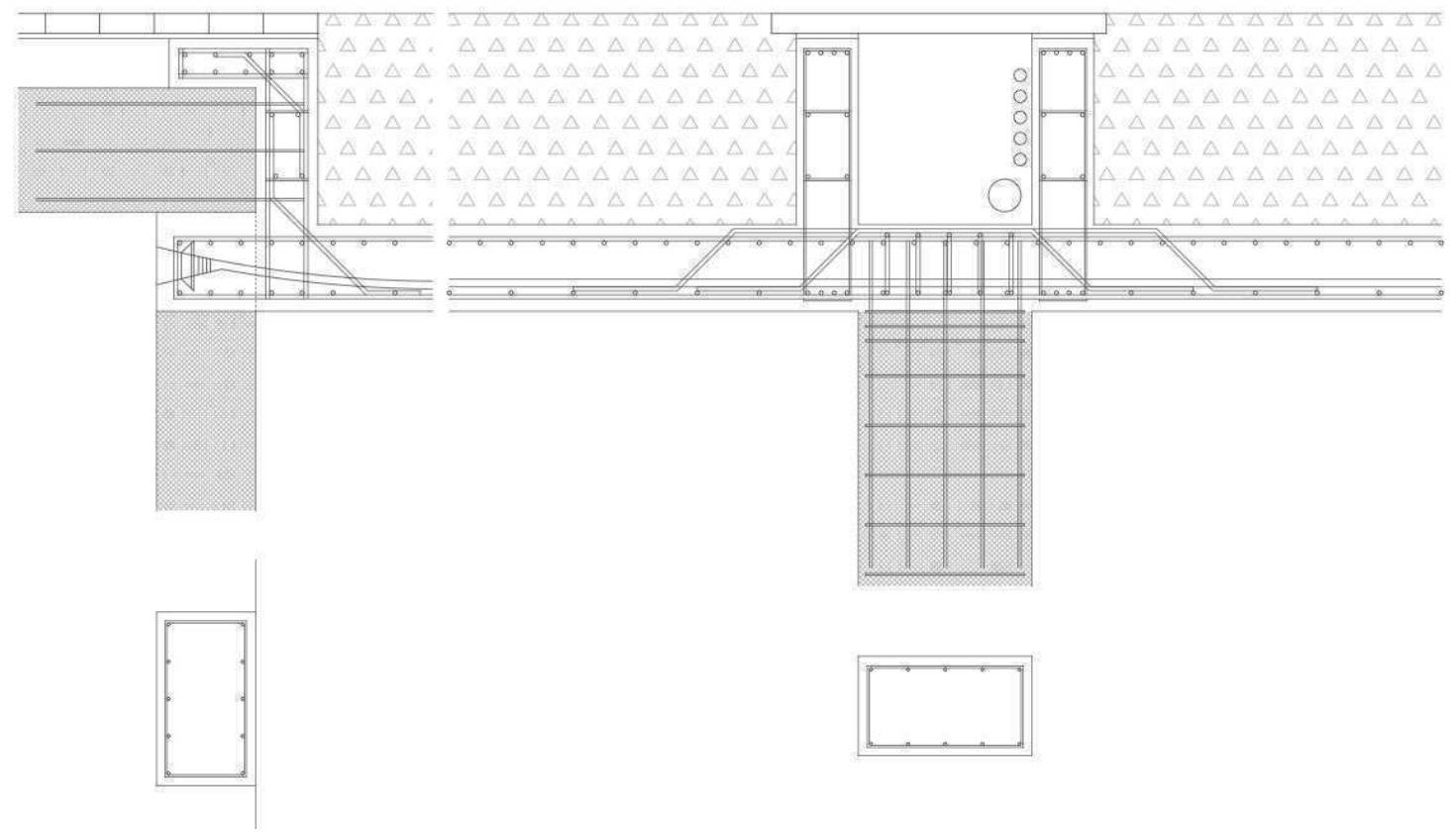

Figure 4.

Detail of the border connection enthe gallery that strengthens the slab, separates the earth on each side of the pedestrian path and holds the tubes for drainage, electricity and watering, $\odot$ VVV.

The entrance and exit points of the garage are transfered from their current position excessively in the center of the square and are now inserted next to the sidewalks in order to maximize the visually free interior space of the garden. Both accesses in Góngora Street and in Joan Valls Street are kept, but are now narrower and they also integrate in the same structural strip the pedestrian entrances and exits with the aim of avoiding a dissemination of volumetric elements that would interrupt the garden. Therefore the intrusion of the parking activity has now been minimized and only the two ramps emerge in volume. The stairs and toilets remain hidden. The access ramps, being located next to the sidewalks, act as effective separators of the danger and noise of road traffic.

In a way they are now the guardians of the Rose Garden as they shield the garden by slightly closing its central space and producing a confined ground where the user perceives the quiet sensation of a protected nature.

The paths of the garden intersect perpendicularly so that the pedestrians can move to any of the four streets that border the Rose Garden. Path crossings also offer larger paved surfaces that support a contemplative function without having to tread the ground. There are no diagonal paths although diagonal lines have been used in the design of the garden. The layout of the green areas of the garden arises from an iterative process on the theme of the nine squares in which the central square has been extended to its maximum dimensions so that children can use it as a playing space located as far away as possible from traffic

\section{Building the virtual earth}

The ground surface on which the new trees and vegetation grow rests on a new concrete slab that will be supported on the existing pillars of the garage.

These pillars have a dimension of $40 \times 70$ centimeters and their disposition is determinant for the layout of the paved paths of the garden since under each path there is a row of pillars. Linking the setup of the paths to the existing concrete pillars aims to increase the resistence 


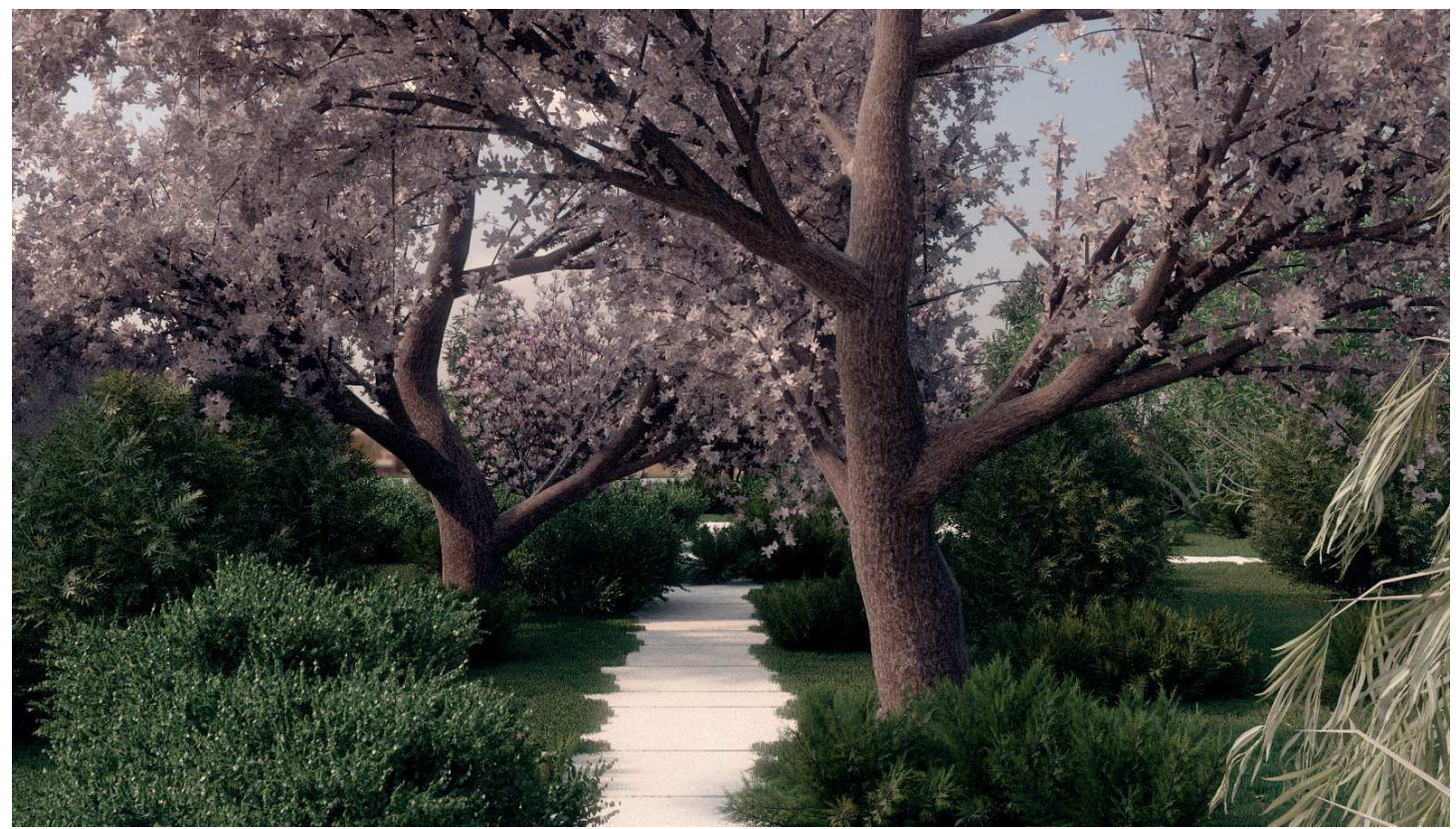

Figure 5.

View of the interior garden along the paved path. (OVVV.

of the slab as each path is built as a gallery in which the walls are two 70 centimeters concrete beams that are used to limit the layer of earth on both sides of the gallery. The pavement rests on the two beams and closes a gallery space free of the weight of the earth. In fact the network of galleries that is formed is useful and necessary to house all the garden facilities such as lighting, irrigation and drainage, which are usually buried and without the possibility of a simple registration or maintenance. So this solution, in a vitruvian way, is at the same time structural, functional and definer of the image of the garden.

The roof slab is thus furrowed by beams that increase its rigidity and therefore allow to reduce its thickness and weight, a prime issue in this project due to the necessary interior height for the garage and the considerable weight and loads of the garden. Although it is possible to implement a 35 centimeters slab solution with abacus, it is preferable to eliminate the presence of the abacuses and build a poststressed slab since the accessibility around the perimeter of the slab is guaranteed as a consequence of the necessary 80 centimeter earth layer. In addition, the technical justification of this solution is found in the fact that the natural waterproofing of the concrete would no longer be affected by microcracking. In a poststressed slab the concrete is compressed and therefore there are no areas of tensile stressed concrete in contact with the earth, as it would happen in the area of the abacuses with the solution of a traditional slab. Waterproofing with bituminous, asphalt or EPDM sheets is not considered due to its deformability and easy accidental breakage, especially because there are better solutions based on mass waterproofing with silicates or waterproof mortars.

The new Rose Garden could be considered as an ideal example for the disposition of that virtual stratum of earth since it benefits from the inclination to optimize the irrigation of its surface. Both Calle Góngora and Joan Valls have an approximate $5 \%$ slope so that, as a consequence, the garden surface has also a $5 \%$ tilt. This allows each piece of land delimited by the gallery-paths to effectively collect the water used for irrigation by different strata of gravels that envelop the drainage pipes. Drainage ensures the health of the roots of the trees by avoiding both the lack of oxygen due to flooding as well as the proliferation of fungi. In addition, the water can be evacuated or used as a continuous renovation for a pond.

For the garden there are several local trees and shrubs such as rowan tree, ash, quercus 


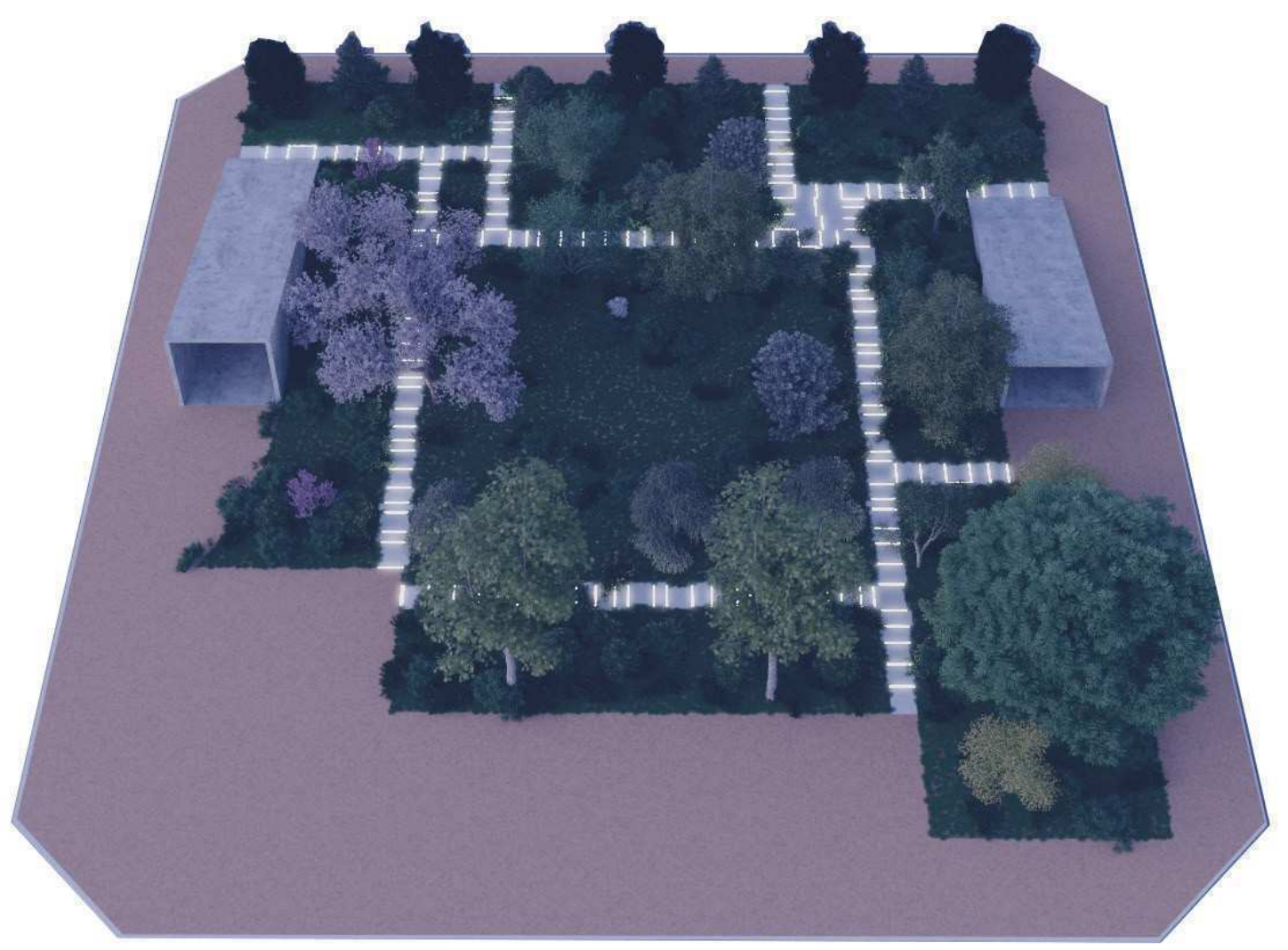

Figure 6.

Aerial view of the Rose garden at night, with the paths lighted. CVVV.

faginea or yew tree (taxus baccata). Other species are also present due to the coloration of their leaves, their flowers or their fruits, such as strawberry tree, jacaranda, Japanese cherry, parrotia persicum or white flower magnolio. In the upper zone there is a row formed by yew trees and cedars, the only conifers of the garden. In the lower zone, the most luxuriant and tallest trees were planted, such as platanus orientalis, acer pseudoplatanus or the Babylonian salix. The roofs that protect the access ramps will be landscaped with rose plants arranged in terraces. The decision has the double objective of avoiding accessibility to the children and to recover the name by which the garden is known: the Rose Garden.

The paths will be paved with granite slabs eight centimeters thick and six different sizes that stand on the walls of the galleries. The granite slabs are arranged irregularly to draw a broken contour in which nature enters and leaves its edges and creates a vibration that would not exist with a precise and straight limit. The contact between the slabs is made by a linear set of glass bricks 6 centimeters thick, named Catolux, that, besides introducing a different texture on the paths, allows a continous illumination. The luminaires are two linear LED beams, of warm and cold light located under the strips of catolux. This solution avoids the emergence of lighting poles that are often subject to vandalism and allows to regulate the intensity and temperature of color more suitable for the different time bands.

\section{Conclusion}

Morphologically the city is recognized from the order of its masses and its gaps. The order comes from the paths of the streets, bridges, squares, interior gardens, outer gardens, parks and rivers, as well as the arrangement of built masses. In terms of relief there is a solid mass represented by the volumes of the building and a hollow mass of streets, squares and gardens where the natural green mass grows. The presence of the green mass results in the 
appearance of a particular atmosphere in urban places and this results in an increase in the environmental value perceived distractedly by the user. When the exterior garden is kidnapped by building pressure or absorbed by the layout of the streets, it is possible to restore that vestige of land to the city by constructing a virtual layer of earth that hides beneath the function or activity that justified that original capture of the earth. To serve the city the land has always been subordinated to the street or to the building, but a time has come when its dearth has produced the appreciation of its value as a morphological unit.

With the garden terrace Le Corbusier recognized the need to restore the land consumed by the imprint of a house and wanted to show that this commitment was part of the architecture of the modern movement. Now we must consider the virtual land as a principle of modernity that allows us to solve not only the old dilemma of land ownership, but also a wide range of conflicts and functional requirements that cities must face and solve at street level. It is the mission of modern urbanism to identify the variables involved in each complex problem that the city presents and to propose solutions in which the environmental quality of the zero level is instituted as a right of the citizen. It is the way to make the identity of the city persist and be reaffirmed in time.

\section{References}

Amelar, Sarah. From railway to greenway. Architecture, 1997 April. v.86, n.4, p.138142

Maldonado, Melissa. Le Jardin Atlantique, Paris. Studies in the history of gardens \& designed landscapes, 2000 Oct.-Dec., v.20, n.4, p. 297-312

Schäfer, Robert. Paris promenades. Topos: European landscape magazine, 2002 Dec., n. 41 , p. $57-62$

Scofidio, Diller and Renfro. The High Line, New York 2004-09. Lotus international 139. Landscape Infrastructures. Editoriale Lotus. Milano 2009. 